\title{
MODERN APPROACHES TO THE FORMATION OF PROFESSIONAL COMPETENCIES OF PHARMACISTS ON ISSUES OF MEDICINES QUALITY ASSURANCE
}

D0I:10.36740/WLek202102130

\author{
Serhii H. Ubohov, Serhii O. Soloviov, Lidiia H. Yurkovska, Violetta I. Todorova \\ SHUPYK NATIONAL MEDICAL ACADEMY OF POSTGRADUATE EDUCATION, KYIV, UKRAINE
}

\begin{abstract}
The aim: To analyze, summarize and substantiate modern approaches to the formation of the professional competencies of pharmacists on issues of medicine quality assurance in Ukraine.

Materials and methods: In this study, we performed systematic review, systematic and comparative analysis, content analysis, generalization, document analysis, logical and graphical modeling to address those issues.

Conclusions: We showed that the curriculum and program of the «Basic foundations of the functioning of quality systems in pharmacy institutions» thematic improvement cycle for pharmacists have been substantiated and developed. The content of the program provides an opportunity to prepare pharmacists for independent work in the field of implementation and support of effective quality systems in pharmacy institutions and hospital pharmacy services. In the context of substantiation of modern approaches to the preparation of pharmacists in the field of medicines quality assurance, the experience and advantages of such modern forms of training of pharmacists as the use of training bases and blended learning have been studied. The modern approaches to the formation of the professional competencies of pharmacists on issues of medicine quality assurance in Ukraine have been analyzed, summarize and substantiated.
\end{abstract}

KEY WORDS: pharmacist, quality assurance, pharmacy institution, pharmaceutical education, postgraduate education, continuous professional development

Wiad Lek. 2021;74(2):334-340

\section{INTRODUCTION}

The effectiveness of the quality systems in pharmacy institutions and hospital pharmacy services depends directly on the availability of competent staff $[1,2]$. Therefore, the study of different aspects of medicine's quality assurance should permeate the curricula and programs for pharmacists at all stages of pharmaceutical education and continuing professional development (CPD).

The first and basic stage of preparation of pharmacy professionals in Ukraine is obtaining higher pharmaceutical education, which is carried out in the institutions of higher pharmaceutical (medical) education (IHE). Until 2017, the obtaining of the incomplete higher pharmaceutical education was carried out in the IHE at the accreditation levels I-II according to the educational and professional program (EPP) of pharmacy professional training of the Junior Specialist Degree in speciality 5.120201 «Pharmacy». After mastering this EPP, such professional was awarded the Pharmacist qualification. The obtaining of the complete higher pharmaceutical education was carried out in the IHE at the accreditation levels III-IV according to the EPP of pharmacy professional training of the Specialist Degree in speciality 7.120201 "Pharmacy». After mastering this EPP, such professional was awarded the Provisor qualification and he was granted the right to perform the professional work of the provisor-intern.
If desired, the provisor could enter the master program and obtain the Master of Pharmacy Degree in speciality 8.120201 «Pharmacy». In 2012, the order of the Ministry of Education and Science of Ukraine No. 1452 of December 20, 2012 approved the branch standard of higher education (BSHE) for the Bachelor of Pharmacy preparation in speciality 6.120201 «Pharmacy», which envisages obtaining basic higher pharmaceutical education in the IHE at the accreditation level II.

In order to bring the titles of pharmacy qualifications in line with the practices of most countries, draft amendments to the National Classifier of Occupations (DK 003:2010) and the Handbook of Qualification Characteristics of Occupations of Workers (Issue 78 «Health Care») have been prepared. In these draft of normative documents, it is proposed to replace the title of Provisor qualification for the Pharmacist and the title of Pharmacist qualification for the Assistant Pharmacist. These draft documents are now under public expert discussion. Given the above, the pharmacist is the professional who has a complete higher pharmaceutical education.

With the adoption of the new wording of the Law of Ukraine "On Higher Education», which introduced five degrees of higher education (Junior Bachelor, Bachelor, Master, Doctor of Philosophy, Doctor of Sciences), the Junior Specialist and Specialist degrees were abolished. The last 




Fig. 1. The main stages of formation of professional competencies of pharmacists on issues of medicines quality assurance

admission to the Specialist Degree was held in 2016. After the entry of this Law into force Specialist, diplomas have been equated to Master degrees. The last admission to the Junior Specialist Degree was held in 2019. Junior Specialist diplomas have been equated to Junior Bachelor degrees.

As of 2018, the BSHE draft for the Master of Pharmacy preparation has been published on the official website of the Ministry of Education and Science of Ukraine. Based on the results of the expert discussion at the level of the professional community and the Scientific and Methodological Subcommittee on Pharmacy of the Ministry of Education and Science of Ukraine, it was decided that further preparation of Masters of Pharmacy would be end-to-end (without Bachelor Degree). That is, after the acceptance of the BSHE for the Master of Pharmacy preparation (planned in 2020), the preparation of Bachelors of Pharmacy will be stopped. Also, as of 2019, the BSHE draft for the Doctors of Philosophy in Pharmacy preparation has been published. The BSHE draft for the Junior Bachelor of Pharmacy preparation is planned to be published in 2020.

A separate branch of knowledge entitled 1202 «Pharmacy» existed in Ukraine until 2015. Resolution of the Cabinet of Ministers of Ukraine No. 266 of April 29, 2015 approved a new list of branches of knowledge and specialities for which higher education applicants are trained. This act, within the 22 «Health Care» branch of knowledge approved the 226 «Pharmacy, Industrial Pharmacy» speciality, which according to the BSHE draft for the Master of Pharmacy preparation includes two specializations: 226.01 «Pharmacy» and 226.02 «Industrial Pharmacy».

\section{THE AIM}

The aim of the study is to analyze, summarize and substantiate modern approaches to the formation of the professional competencies of pharmacists on issues of medicines quality assurance in Ukraine.

\section{MATERIALS AND METHODS}

Research methods are: systematic review, systematic and comparative analysis, content analysis, generalization, document analysis, logical and graphical modeling.

\section{REVIEW AND DISCUSSION}

We have studied and summarized the main stages of formation of professional competencies of pharmacists 
Table I. The content of professional competences of the graduates of the Master of Pharmacy degree program, related to issues of assurance and control of medicines quality

\begin{tabular}{cc}
\hline Designa-tion & $\begin{array}{c}\text { The brief content of competence that implies the ability to perform } \\
\text { the following types of work }\end{array}$ \\
\hline
\end{tabular}

1. Pharmaceutical competencies in the field of health care*

\begin{tabular}{|c|c|}
\hline PC 1 & To carry out sanitary-enlightenment work among the population \\
\hline PC 2 & $\begin{array}{l}\text { To advise on the use of prescription and over-the-counter medicines, perform pharmaceutical care during the } \\
\text { selection and realization of over-the-counter medicines }\end{array}$ \\
\hline & 2. Competence in the field of providing pharmaceutical assistance to the population \\
\hline PC 4 & To ensure rational use of prescription and over-the-counter medicines \\
\hline PC 5 & To monitor the effectiveness and safety of medicines use \\
\hline PC 7 & $\begin{array}{l}\text { To ensure proper storage of medicines according to their physicochemical properties and Good Storage Practice } \\
\text { (GSP) regulations in pharmacy institutions and hospitals }\end{array}$ \\
\hline
\end{tabular}

3. Organizational and managerial competences

\begin{tabular}{|c|c|}
\hline PC 8 & $\begin{array}{l}\text { To organize pharmacy activities in accordance with Good Pharmacy Practice (GPP) regulations and conduct } \\
\text { commodity analysis }\end{array}$ \\
\hline PC 10 & $\begin{array}{l}\text { To develop, implement and apply management approaches in the professional activity of pharmacy institutions } \\
\text { and pharmaceutical enterprises, demonstrate leadership skills }\end{array}$ \\
\hline \multicolumn{2}{|r|}{ 4. Professional and personal competences } \\
\hline PC 12 & To use knowledge of legal acts and recommendations of good pharmacy practices in professional activities \\
\hline PC 13 & $\begin{array}{l}\text { To demonstrate and use communication skills, principles of pharmaceutical ethics in accordance with the Code of } \\
\text { Ethics for Pharmaceutical Workers of Ukraine, and WHO recommendations in practice activities }\end{array}$ \\
\hline PC 14 & $\begin{array}{l}\text { To organize and carry out production activity of pharmacies for the manufacture of medicines in accordance with } \\
\text { Good Pharmacy Practice (GPP) regulations }\end{array}$ \\
\hline
\end{tabular}

Good Pharmacy Practice (GPP) regulations
To organize and participate in the production of medicines in the conditions of pharmaceutical enterprises in
accordance with Good Manufacturing Practice (GMP) regulations, with appropriate development and registration
of necessary documentation. To determine the stability of medicines

To organize and carry out collection of medicinal herbal raw materials (MHRM) in accordance with Good
PC 16 Agricultural and Collecting Practice (GACP) regulations as a guarantee of quality of MHRM on it

5. Competencies in the field of quality management and quality control of medicines

PC 18 To develop and implement quality management systems for pharmaceutical enterprises and pharmacy institutions in accordance with standards, perform quality audits and manage risks for the medicines quality

To organize and carry out medicines quality control in accordance with the requirements of State Pharmacopoeia

PC 19 of Ukraine and good pharmaceutical practices, determine the methods of sampling for the control of medicines and carry out their standardization in accordance with current requirements, prevent the spread of falsified medicines

PC 20 To develop methods of medicines quality control, including active pharmaceutical ingredients, medicinal plant raw materials and excipients using various control methods

*The division of special (professional) competences into five clusters is carried out in accordance with the Global Competence Framework for pharmacy specialists of the education initiative of International Pharmaceutical Federation (FIP), taking into account national peculiarities of preparation for higher pharmaceutical education applicants.

on issues of medicines quality assurance. The analysis have showed that the basic competences on these issues are acquired by students of IHE on speciality «Pharmacy, Industrial Pharmacy», while studying specialized pharmaceutical disciplines in senior courses (3-5 courses) [3]. Increasing the level of practical preparation, acquiring new and improving the previously acquired competencies of graduate pharmacists is carried out in the institutions of postgraduate pharmaceutical (medical) education (IPGE) at the stages of postgraduate education (PGE) and CPD (Figure 1). According to the Regulation on the system of continuing professional development in the field of health care, approved by Resolution of the Cabinet of Ministers of Ukraine No. 302 of March 28, 2018, the services for the $\mathrm{CPD}$ of pharmacists may also be provided by other providers of educational services (higher education institutions, research institutions, health care institutions, professional associations, etc.).

We have analyzed the list of competencies of the graduate with the Master of Pharmacy qualification, related to the issues of assurance and control of medicines quality and identified in the corresponding BSHE draft. The analysis 


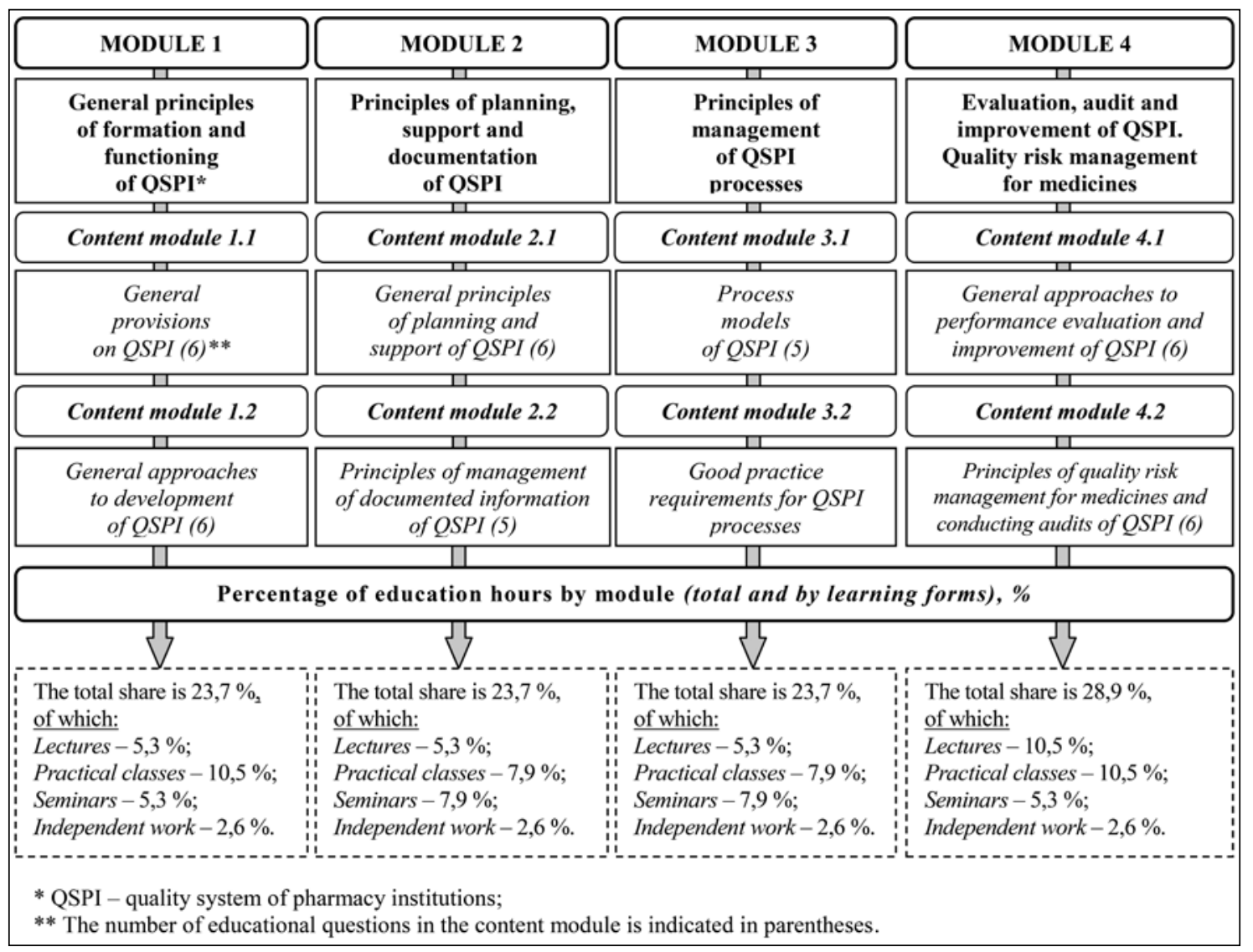

Fig. 2. The structure of curriculum and program of the «Basic foundations of the functioning of quality systems of pharmacy institutions» pharmacists' thematic improvement cycle

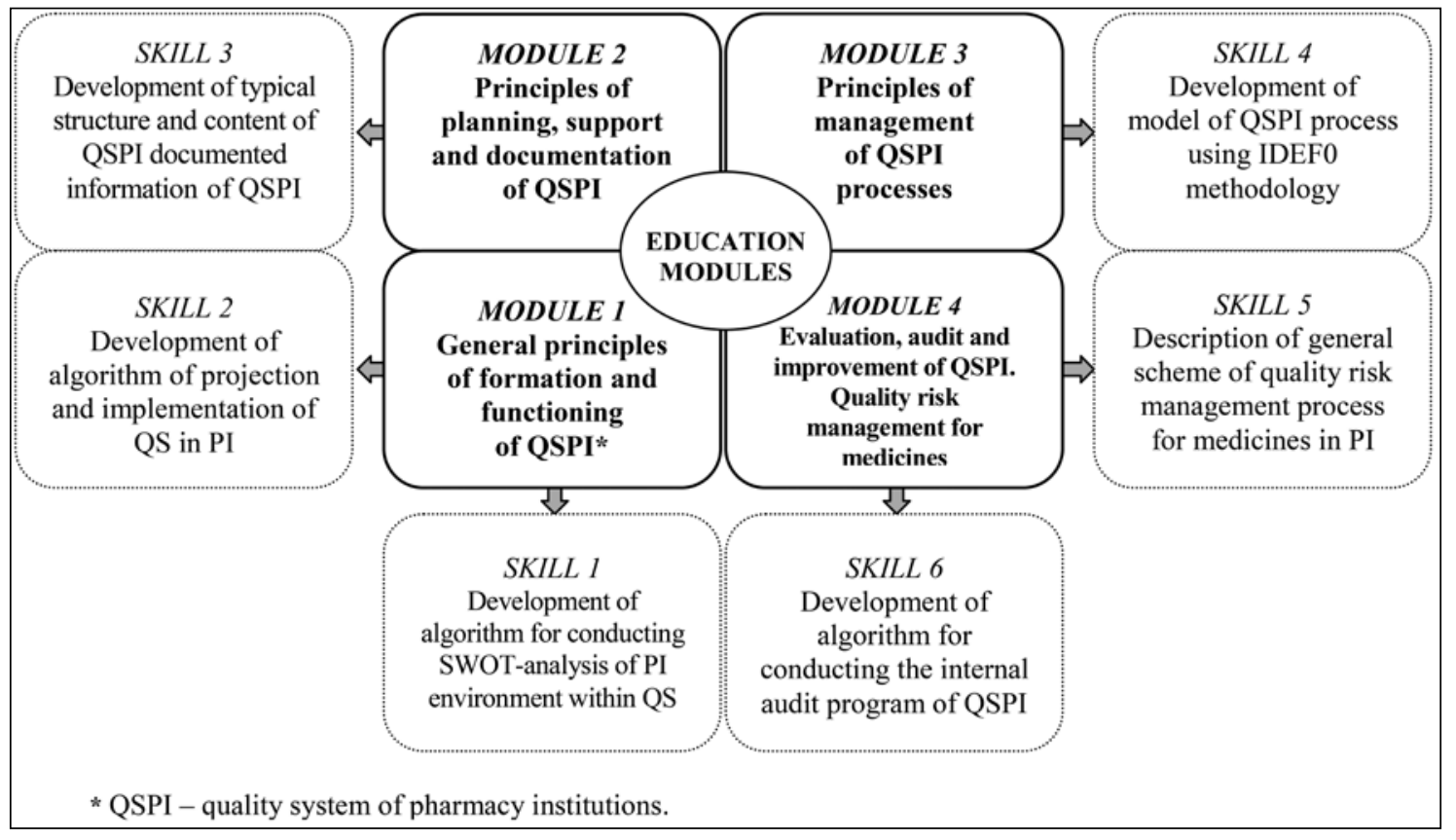

Fig. 3. The scheme of formation of practical skills within the «Basic foundations of the functioning of quality systems of pharmacy institutions» pharmacists thematic improvement cycle

conducted showed that the content of the integral, 14 general and 15 of the 20 identified by the BSHE draft special (professional) competencies corresponds to the tasks facing the specialists who are responsible for as- surance and control of medicines quality at the stages of production, wholesale and retail realization. The analysis of the program learning outcomes identified in the BSHE draft for the Master of Pharmacy preparation shows that 
they are fully consistent with the content of competencies described in the Table I.

In the context of studying the current state of preparation of pharmacy specialists at the stages of PGE and CPD, the educational activity of the Department of Quality Control and Standardization of Medicines of Shupyk National Medical Academy of Postgraduate Education has been analyzed. So, in recent years the department has been teaching the main issues of medicines quality assurance on cycles of internship or primary specialization (for persons who obtain the specialist certificate in speciality "General Pharmacy»), secondary specialization (for persons who obtain the specialist certificate in speciality "Analytical and Control Pharmacy»), probation (cycles for persons who confirm the Pharmacy specialist certificate in relevant specialty) and pre-attestation preparation (cycles for persons applying for assignment of the Pharmacist Qualification Category in relevant speciality) within the courses «Pharmaceutical Analysis of Medicines», "Quality, Standardization and Certification of Medicines», "Assurance, Control of Quality and Standardization of Medicines», "Pharmacognosy».

The most topical aspects of medicines quality assurance are taught at the thematic improvement cycles (TIC), whose programs are constantly updated. So, during 2014-2018, the department conducted the «Topical issues of quality assurance and prevention of the spread of falsified medicines» TIC for pharmacists-analysts, chemists-analysts, heads of pharmacy institutions and Responsible persons in medicines quality. At present, much of the issues previously taught at these cycles are included in the Internship program, as well as the educational programs «Pharmacy» that are taught in IHE and provide for the study by students of 5 th year course of new narrow normative and selective disciplines on medicines quality assurance («Standardization of Medicines», "Good Pharmacy Practices», "Assurance and Control of Medicines Quality», etc.). Given this, it becomes obvious the need for the development and implementation of the short-term TIC with elements of distance learning in the educational process, which would provide the formation of a high level of professional competence of pharmacy professionals, in particular on the implementation of effective quality systems in pharmacy institutions [4].

In the context of the above mentioned, we have been worked out the curriculum and program of the «Basic foundations of the functioning of quality systems in pharmacy institutions» thematic improvement cycle for pharmacists. The aim of this cycle is to acquire professional competencies in the development, implementation and support of effective functioning of quality systems in pharmacy institutions (pharmacy warehouses, manufacturing and retail pharmacies, pharmacy chains) and hospital pharmacy services $[5,6]$. The contingent of this TIC may involve the pharmacists of different specialities, including those who perform the functions of Responsible persons in medicines quality, hold the positions of heads of pharmacy institutions, quality services of wholesale and retail pharmaceutical enterprises, hospital pharmacy services, specialists of the State Service of Ukraine on Medicines and Drugs Control, and scientific-pedagogical workers of IHE and IPGE, which provide training to pharmacy specialists at the stage of PGE and CPD. The TIC program includes four education modules, each of which contains two content modules, and provides for the study of the following issues: general principles of formation and functioning of quality system of pharmacy institutions (QSPI); principles of planning, support and documentation of QSPI; principles of management of QSPI processes; general approaches to monitoring, evaluation, audit and improvement of QSPI; quality risk management for medicines $[7,8,9]$. In addition to the lecture classes, the program also envisages time for extracurricular independent work without the participation of the lecturer. Education hours along the forms of training include: lectures $-26,3 \%$, practical classes $-36,9 \%$, seminars $-26,3 \%$, independent work $-10,5 \%$ of the total number of academic hours, respectively. The structure of curriculum and program of the TIC is presented in the Figure 2.

The TIC program, along with the study of different aspects of the implementation and functioning of quality systems in pharmacy institutions, also envisages study issues of the formation of quality systems in hospital pharmacy services, which is part of the entire quality management system (QMS) of hospitals. In total, the TIC program contains 46 study questions, on the basis of which education topics are formed and a thematic plan is developed.

Forms of control of the educational process include the assessment of the level of mastering practical skills and oral test. In the framework of our work, a list of theoretical questions to the test and standards of practical skills have been developed. At the same time, the list of practical skills developed covers all four modules of the TIC program (Figure 3).

The duration of training on the cycle is 0,5 months ( 78 education hours) and in shortened form - 0,25 months (39 education hours). The organization of training can be conducted in full-time and full-time/part-time forms with the elements of distance learning. The share of distance hours in distance learning is about $50 \%$ of the total academic hours within the cycle. Distance learning involves online and offline communication, using email, video, and online learning resources.

Thus, the implementation of short-term TIC with the elements of distance learning at the CPD stage is one of the most effective forms of improving the professional competence of pharmacy specialists on the issues of QSPI functioning. The content of the education material of TIC program developed by us makes it possible to prepare pharmacists for independent work in the field of implementation and support of effective QS in pharmacy institutions and hospital pharmacy services. The further perspective is the development of highly specialized one-, two-day programs for intensive training of pharmacists on the most topical issues of functioning of QSPI, which involves the use of current forms of training (seminars, 
trainings, webinars, master classes, etc.) and active use of video resources.

In the context of the substantiation of modern approaches to the training of pharmacy specialists on issues of medicines quality assurance, we have studied the experience and benefits of using modern forms of training at the stages of PGE and CPD of pharmacists. The modern approaches to the preparation of pharmacists require the implementation of new forms of training in the educational process, the development of the most favorable conditions for the acquisition of program material, the formation of skills and abilities. One of the way to the optimization of training on the pharmacists' refresher cycles is to use training bases that are selected according to the requirements of curriculum and program. Many years of experience of the department show that conducting classes on training bases increases the interest of listeners to the studies, allows to present the education material in a most qualitative, clear and comprehensive way, which is not always possible in the lecture class. It creates the opportunity to involve highly qualified practitioner specialists without the interruption of work for teaching, and promotes the use of new forms and methods of training.

So, the department actively implements different modern forms of seminars, such as: scientific and practical seminar, Flash seminar, blitz seminar, seminars in the form of conversation, debate, conference, consultation, presentation, excursion, exhibition, round table, colloquium, practical work, training, master class, situational games, etc. At the classes held at the training bases, due attention is paid to the issues of medicines quality assurance, in particular the activities of Responsible persons on medicines quality, the methodology of conducting input control of medicines in pharmacy institutions and hospitals, mastering current methods of pharmaceutical analysis, prospects for the development and standardization of medicines, including herbal medicines and dietary supplements $[3,5]$.

It should also be noted that blended learning has been rapidly developing in the system of PGE and CPD for medical and pharmaceutical professionals, which involve the combination of distance and e-learning with traditional forms, such as full-time and part-time studies. The implementation of blended learning methods provides for the intensification, modernization of education process and increases its efficiency. The blended learning model assumes that part of the learning activity is spent by the listener in the classroom, and part is taken to a distance form, dominated by independent types of work. At the same time, it is important for the teacher to determine what types of listener activities should be used in face-to-face classes, and what types can be transferred to an independent distance form. Thus, the face-to-face form provides listeners with new material to familiarize themselves with the most difficult problems that require the direct involvement of the teacher. In the classroom, the teacher conducts discussions, work in groups, that is, activities that require direct contact at different levels (with the teacher, between the listeners, etc.). Distance learning includes independent research activities, practical work and group assignments, consultations with the teacher, conducting tests.

The department has accumulated considerable experience in the use of blended learning forms during the conduct of cycles on thematic improvement, specialization, probation, pre-attestation preparation in specialities «Analytical and Control Pharmacy» and "General Pharmacy». The first stage of implementation of blended learning methods at the department has been characterized by an increase in the share of teachers with extensive experience in practical work, optimization of the "listener - teacher» ratio (1:5), expansion of the register of training bases, active use of computer programs for testing and presentations (mainly in PowerPoint). At the second stage, the resources of local and global networks, e-learning tools (teaching materials, manuals, textbooks, electronic versions of pharmacopoeia, etc.) have been put to use. The modern forms of seminars and elements of online learning through the Internet have been implemented. At present, the department is on the threshold of the third stage, which is related to the development of different models of learning management and approaches to the evaluation of its quality and effectiveness, the development of software systems that provide a comprehensive solution to the problems of blended learning (learning content management systems, systems of testing and monitoring of learning outcomes, interactive support systems of learning environment and learning management systems). It is possible to implement this stage only if the high level of competence of the teachers of the department will be ensured in the following areas: the development of high-quality electronic educational and methodological complex for the discipline; scenario development of study of disciplines in the blended form; providing pedagogical support for the process of study disciplines by listeners on the individual educational trajectory (tutorial support); evaluation of learning outcomes of listeners and systematic monitoring of the learning process quality in the blended form to correct the elements of the system of professional training of specialists; providing educational communications by means of email, audio and video. Thus, the implementation of the blended learning model at the stages of PGE and CPD increases the efficiency of professional training of pharmacists, both interns and listeners of refresher courses.

\section{CONCLUSIONS}

The current state and content of preparation have been analyzed and main stages of formation of professional competencies of pharmacists on issues of quality assurance and quality control of medicines at the stages of obtaining higher education, PGE and CPD have been summarized.

The curriculum and program of the «Basic foundations of the functioning of quality systems in pharmacy institutions» thematic improvement cycle for pharmacists have been substantiated and developed. The content of the program provides an opportunity to prepare pharmacists for independent work in the field of implementation and 
support of effective quality systems in pharmacy institutions and hospital pharmacy services.

In the context of substantiation of modern approaches to the preparation of pharmacists in the field of medicines quality assurance, the experience and advantages of such modern forms of training of pharmacists as the use of training bases and blended learning have been studied.

\section{REFERENCES}

1. Horodetska V.I., Lebedynets V.0., Kovalenko S.M. Analysis of the competence characteristics of quality management specialists at the domestic pharmaceutical enterprises. Manag. Econ. Qual. Assur. in Pharm. 2013; 4 (30): 38-44.

2. Diakova L.Yu., Nemchenko A.S., Nosenko 0.A. Management of internal training and improvement of pharmacy staff in the context of good practice (GDP and GPP). Farmakom. 2009; 2: 125-132.

3. Vetiutneva N.0., Ubohov S.H., Rymar M.V., Pylypenko H.H. et al. Current concept of medicines quality assurance. Collective monograph, 1st ed. Vinnytsia: Nilan-LTD. 2018: 400.

4. Ubohov S.H., TrokhymchukV.V., Todorova V.I.,Zahoriy V.A. Process model of the pharmaceutical integrated management systems. Wiad. Lek. 2019; 72(2): 201-208.

5. Tolochko V.M., Artiukh T.0. Determination the purpose and implementation of the planned actions of the responsible person for medicines quality control of the pharmacy institution. Ukr. Bull. Psychoneurol. 2011; 19 (67): 107-109.

6. Chukreeva N.V., Maksimkina E.A. Responsibilities of responsible for quality in the field of wholesale distribution of medicines. Pharmacy. 2009; 5: 26-30.

7. Lebedynets V.O. Determination of the role and main functions of management personnel in the formation and maintenance of the functioning of the quality management system at the enterprises for the production of medicines. Manag. Econ. Qual. Assur. in Pharm. 2013; 5(31): 9-14.

8. PodpruzhnikovYu.V., Ishmukhametov A.A., Nemchenko A.S., Andriukova L.N. et al. Chrestomathy of Pharmaceutical Quality. Moscow: Gruppa Remedium. 2015: 432.

9. TrokhymchukV.V., UbohovS.H., Zagoriy V.A. Methodological approaches to quality risk management in the pharmacy institutions. Recipe. 2018; $6(21): 872-882$.
Authors are grateful to the staff of the Faculty of Preventive Medicine and Pharmacy of the Shupyk National Medical Academy of Postgraduate Education who agreed to participate in the study for their cooperation, time, and motivation. This work was performed within the framework of the research work of the Department of Quality Control and Standardization of Medicines "Substantiation of methods of increasing solubility of substances, methods of quality control and organizational and methodological aspects of the integrated model of quality assurance medicines at the stages of realization and medical use» (state registration number 0115U002158). The authors declare no conflict of interest.

\section{ORCID and contributionship:}

Serhii H. Ubohov: 0000-0002-9684-7323 A,B,C,D,F

Serhii O. Soloviov: 0000-0003-2681-7417 D,E

Lidiia H. Yurkovska: 0000-0002-2695-5433 ${ }^{B}$

Violetta I. Todorova: 0000-0003-3642-4318

\section{Conflict of interest:}

The Authors declare no conflict of interest.

\section{CORRESPONDING AUTHOR Serhii H. Ubohov}

Shupyk National Medical Academy of Postgraduate Education 9 Dorohozhytska st., 04112 Kyiv, Ukraine

tel: +38(067)-231-76-56

e-mail:ubogov@ukr.net

Received: 16.05 .2020

Accepted: 25.11 .2020

A - Work concept and design, B - Data collection and analysis, C - Responsibility for statistical analysis, D-Writing the article, $\mathbf{E}$-Critical review, $\mathbf{F}$ - Final approval of the article 